\title{
Improving the corrosion performance of hybrid sol-gel matrix by modification with phosphonic acid
}

\author{
Viviane Dalmoro $^{\mathrm{a}, \mathrm{b}, \mathrm{c}}$, João H.Z. Santos ${ }^{\mathrm{a}}$, Ione M. Baibich ${ }^{\mathrm{a}}$, Ian S. Butler ${ }^{\mathrm{d}}$, Elaine \\ Armelin $^{\mathrm{b}, \mathrm{c}}$, Carlos Alemán ${ }^{\mathrm{b}, \mathrm{c}}$, Denise S. Azambuja ${ }^{\mathrm{a}, *}$ \\ ${ }^{a}$ Instituto de Química, Universidade Federal do Rio Grande do Sul \\ Av. Bento Gonçalves 9500 - CEP 91501-970, Porto Alegre, RS, Brazil \\ ${ }^{\mathrm{b}}$ Departament d'Enginyeria Química, ETSEIB, Universitat Politècnica de Catalunya, \\ Avda. Diagonal 647, Barcelona E-08028, Spain \\ ${ }^{c}$ Center for Research in Nano-Engineering, Universitat Politècnica de Catalunya, \\ Campus Sud, Edifici C', C/Pasqual i Vila s/n, Barcelona E-08028, Spain \\ ${ }^{\mathrm{d}}$ Department of Chemistry, McGill University, 801 Sherbrooke St. West, Montreal, \\ Quebec, Canada H3A 2K6 \\ *Corresponding author: denise@iq.ufrgs.br, Fax: 555133087304, Phone:
}

555133087214

\begin{abstract}
Sol-gel films were prepared using different ratios of two silica precursors, vinyltrimethoxysilane (VTMS) and tetraethylorthosilicate (TEOS), targeting the anticorrosion treatment of aluminum alloy 2024-T3. The electrochemical behavior of the alloy coated with such films, which was studied in a $0.05 \mathrm{~mol} \mathrm{~L}^{-1} \mathrm{NaCl}$ solution, revealed that the VTMS/TEOS ratio drastically affects the anticorrosion performance. Electrochemical impedance spectroscopy (EIS) results provided evidences that the best anticorrosive response occurs with the films prepared from $50 \% \mathrm{v} / \mathrm{v}$ ethanol, $46 \% \mathrm{v} / \mathrm{v}$ water, $3 \% \mathrm{v} / \mathrm{v}$ VTMS and $1 \% \mathrm{v} / \mathrm{v}$ TEOS. Moreover, the effects of the addition of ethylenediamine tetra(methylene phosphonic acid) (EDTPO) to a hybrid sol-gel matrix were examined. The corrosion resistance was considerably improved when the concentration of added phosphonic acid was $3.75 \times 10^{-5} \mathrm{~mol} \cdot \mathrm{L}^{-1}$. Scanning electron microscopy, energy dispersive X-ray spectroscopy and X-ray photoelectron spectroscopy analyses revealed that EDTPO-containing films provide a more uniform coverage. Results evidenced the formation of $\mathrm{Si}-\mathrm{O}-\mathrm{Al}$ linkages in the VTMS/TEOS and VTMS/TEOS/EDTPO systems and that the VTMS/TEOS/EDTPO system contained $\mathrm{P}-\mathrm{O}-\mathrm{Al}$ linkages. The $\mathrm{P}-\mathrm{O}-\mathrm{Al}$ bonds, combined with the silica network action, may be responsible for the good anticorrosive behavior of the VTMS/TEOS/EDTPO films.
\end{abstract}

Keywords: surface modification; corrosion resistance; silane. 


\section{Introduction}

Environmental restrictions have led to the accelerated development of new environmentally friendly coating technologies at both the academic and industrial levels. In this context, sol-gel coatings have been investigated as potential replacements for chromate-based surface treatments for several metals [1-5]. Different silane derivatives have been used to protect metals from corrosion by forming a thin coating that acts as a physical barrier to delay the access of aggressive species to the substrate. The molecular structure, degree of organization and properties of the resulting sol-gel materials depend on the chemical nature of their components [6]. Thus, the choice of silane is a critical task.

Previous studies have shown that silanes bearing vinyl groups improve the corrosion resistance of aluminum and its alloys [7-12], iron [13], galvanized steel [14], and cooper [11]. According to Bajat et al. [10], the performance of vinyltriethoxysilane (VTES) films on $99.5 \% \mathrm{Al}$ was satisfactory, even in presence of a high concentration of chloride ions $(3 \% \mathrm{NaCl})$. Such performance was shown to depend on both the concentration of the silane solution and the curing time. The longest curing time (30 min) and greatest VTES concentration ( $5 \% \mathrm{v} / \mathrm{v})$ improved the corrosion protection, which was attributed to an enhancement of the silane crosslinking and to the formation of a more hydrophobic and thicker film [10].

Previous studies on the performance of silane films formed from mixtures of TEOS and silanes bearing vinyl groups are very scarce. Among the few published studies, Hu et al. [15] evaluated two precursor systems of silica, (i.e. TEOS and TEOS/VTES) onto magnesium alloy AZ91D. Scanning electronic microscopy (SEM) images of TEOS films revealed the presence of some white particles and cracked areas produced by agglomeration of $\mathrm{SiO}_{2}$ during the heating process $\left(350{ }^{\circ} \mathrm{C}\right.$ for $2 \mathrm{~h}$ ), which 
reduced the corrosion protection. In contrast, TEOS/VTES coatings subjected to the same heating process showed a more compact structure and good barrier properties for the protection of the magnesium alloy.

Another key point for the design of more environmentally friendly and efficient treatments is the use of starting solutions with relatively low alcohol concentrations. Sol-gel chemistry is well known to consist primarily of hydrolysis and condensation reactions of alkoxysilane precursors. The ratio between the water content and the hydrolysable alkoxysilane silane content determines the condensation and growth mechanism of the sol-gel matrix [6].

On the other hand, phosphonic acids are an important class of self-assembled molecules with high ability to react with a range of metal oxide surfaces [16], which has been proposed as a new method for corrosion protection [17-19]. The formation of phosphonate layer was shown to be a spontaneous process that could be accomplished by simple immersion of the metal into the phosphonic acid solution [17]. Thus, metalophosphonate bonds (Me-O-P) are formed through a condensation reaction [16]. This seemingly simple process depends on the metal substrate [20], the chemical nature of the phosphonic acid $[18,19]$, and the $\mathrm{pH}$ of the solution [21], thereby requiring a careful assessment.

Previous studies were devoted to investigate the addition of phosphonic acid onto TEOS, evidencing a remarkable improvement of the corrosion performance for the AA2024 alloy coated with films of such combined system [22,23]. However, the silica network produced by TEOS exhibited hydrophilic characteristics, which resulted in poor corrosion protection [22]. The main aim of the present study, which represents a significant extension of those previous works, is to evaluate the improvement of the anticorrosive performance of coatings with vinyltrimethoxysilane (VTMS). More 
specifically, in this work we study the influence of both $(i)$ the VTMS/TEOS ratio and (ii) the concentration of ethylenediamine tetra(methylene phosphonic acid) (EDTPO) added to the VTMS/TEOS sol-gel matrix on the corrosion protection of the AA2024 alloy. For this purpose, the anticorrosion properties of the coated samples were investigated using electrochemical impedance spectroscopy (EIS) measurements after different immersion times in a $0.05 \mathrm{~mol} \mathrm{~L}^{-1} \mathrm{NaCl}$ solution. The chemical structures of the films were determined by FTIR spectroscopy, whereas the morphologies and compositions of films were examined by SEM, energy dispersive X-ray spectroscopy (EDX) and X-ray photoelectron spectroscopy (XPS).

\section{Experimental}

\subsection{Pretreatment}

AA2024-T3 samples were prepared by grinding with silicon carbide papers up to 1200 grit, being subsequently immersed in a $0.05 \mathrm{~mol} \mathrm{~L}^{-1}$ acetic acid solution for $5 \mathrm{~min}$. After this, the samples were washed with distilled water and dried under a hot air stream. We verified that this pretreatment decreased the $\mathrm{Cu}$ amount on the metallic surface resulting in the reduction of galvanic corrosion and the increment on metalosiloxane and metal-phosphonic bonds, as reported in a study previously conducted in our group [22].

\subsection{Coating Deposition}

For the preparation of the starting solutions, TEOS (Merck, $98 \%$ ), VTMS (Aldrich, $97 \%$ ), ethanol (Nuclear, $99.5 \%$ ) and deionized water $(18.3 \mathrm{M} \Omega \mathrm{cm}$ ) were mixed in the proportions (v/v) described in Table 1, which also shows the abbreviations used for their identification. Starting solutions containing phosphonic acid were 
prepared by dissolving EDTPO in deionized water, being their compositions displayed in Table 1.

Starting solutions were stirred for $1 \mathrm{~h}$ at room temperature and were then stored for 3 days prior to their use. Immediately after their pretreatment, AA2024-T3 samples were immersed in starting solution for $30 \mathrm{~min}$, being the withdrawal rate of $20 \mathrm{~cm} \mathrm{~min}^{-}$ 1 , and cured in an oven at $110{ }^{\circ} \mathrm{C}$ for $1 \mathrm{~h}$ [22]. The thickness of the films, which was measured by profilometry Dektack Veeco 150, was ca. $145 \mathrm{~nm}$ for $1 \mathrm{~V}$ samples and for other films this value is between $190-200 \mathrm{~nm}$.

\subsection{Measurements}

\subsubsection{Electrochemical impedance spectroscopy}

Electrochemical measurements were performed using an AUTOLAB PGSTAT 30/FRA 2 system. A three-electrode electrochemical cell arrangement was used and consisted of a AA2024-T3 panel with $1 \mathrm{~cm}^{2}$ of exposed area (working electrode), a saturated calomel electrode (SCE) (reference electrode), to which all of the potentials are referred, and a Pt mesh (counter electrode). EIS measurements were performed in the potentiostatic mode at the open-circuit potential (OCP). The amplitude of the EIS perturbation signal was $10 \mathrm{mV}$, and the studied frequency range was $10^{5}$ to $10^{-2} \mathrm{~Hz}$. Experiments were performed at $25{ }^{\circ} \mathrm{C}$, and a $0.05 \mathrm{~mol} \mathrm{~L}^{-1} \mathrm{NaCl}$ solution was employed. At least three samples were evaluated for each condition.

\subsubsection{FTIR spectroscopy}

Fourier-transform reflection-absorption infrared (FTIR-RA) spectra of films deposited onto AA2024 were obtained using a Nicolet 6700 FT-IR spectrometer equipped with a Smart SAGA (Specular Aperture Grazing Angle) accessory and Omnic software. 
Spectra were collected with an incidence angle of $80^{\circ}$ from the normal surface at a resolution of $4 \mathrm{~cm}^{-1}$ (total of 512 scans), using a polished bare aluminum alloy as background.

\subsubsection{Scanning electron microscopy}

SEM studies were carried out using a focused-ion-beam Zeiss Neon 40 scanning electron microscope equipped with an energy-dispersive X-ray (EDX) spectroscopy system and operating at $5 \mathrm{kV}$. Samples were mounted on a double-sided adhesive carbon disc and sputter-coated with a thin layer of carbon to prevent sample charging problems.

\subsubsection{X-Ray photoelectron spectroscopy}

XPS analyses were performed in a SPECS system equipped with a high intensity twin anode X-ray source XR50 of Mg/Al (1253 eV/1487 eV) operating at $150 \mathrm{~W}$, placed perpendicular to the analyzer axis, and using a Phoibos 150 MCD-9 XP detector. The X-ray spot size was $650 \mu \mathrm{m}$. Samples were fixed mechanically into a special sample holder using a double side tape. The spectra were recorded with a pass energy of $25 \mathrm{eV}$ in $0.1 \mathrm{eV}$ steps at a pressure below $6 \cdot 10^{-9}$ mbar. The $\mathrm{C} 1 \mathrm{~s}$ peak was used as an internal reference with a binding energy of $284.8 \mathrm{eV}$. The atomic percentage of each element was determined by dividing the peak area of the most intense XPS signal of each element by the corresponding sensitivity factor and expressing it as a fraction of the sum of all normalized peak areas. High resolution XPS spectra were acquired by Gaussian/Lorentzian curve fitting after S-shape background subtraction.

\subsubsection{Water Contact Angle}


Water contact angle (WCA) of films was measured at ambient temperature using a sessile drop method. A 4-6 $\mu \mathrm{L}$ droplet of deionized water was deposited on the aluminum alloy coated with sol-gel film. After with a digital microscope the crosssection was observed. The values reported are averages of several measurements performed in different areas of each sample surface, being that for each system three panels were analyzed. WCA values were calculated using the software package Surftens v. 3.0 .

\section{Results and Discussion}

\subsection{Comparison of ratio VTMS/TEOS}

\subsubsection{Spectroscopy characterization by FTIR-RA}

FTIR spectroscopy is a powerful technique for monitoring the evolution of hydrolysis and condensation reactions during the sol-gel process [23,24] and the formation of the silica network $[11,25,26]$. Figure 1 shows the FTIR spectra for the films formed on AA2024 substrates with different VTMS/TEOS ratios. The same bands are detected for all films. The vibration frequencies of these films are provided in the Supporting Information (see Table S1).

The spectra of films (Figure 1) depict a broad and weak band in the region of $3500-3200 \mathrm{~cm}^{-1}$ related to $\mathrm{O}-\mathrm{H}$ stretching [23-28] and another band at $1602 \mathrm{~cm}^{-1}$ associated with the $\mathrm{C}=\mathrm{C}$ stretching of vinyl groups [11,29]. Other bands of vinyl moieties are detected at 1412 and $1278 \mathrm{~cm}^{-1}$ attributed to $\mathrm{CH}_{2}$ in-plane deformation and $\mathrm{C}-\mathrm{H}$ rocking $[11,26,29]$, respectively. A strong band detected around $1190 \mathrm{~cm}^{-1}$ has been attributed to the $\mathrm{Si}-\mathrm{O}$ asymmetric stretching of $\mathrm{Si}-\mathrm{O}-\mathrm{Si}[25-28,30]$. This is accompanied by a broad shoulder (1110 to $1000 \mathrm{~cm}^{-1}$ ). Some authors [25,27] have reported the deconvolution of this part of the spectrum, indicating that it is composed by 
transversal and longitudinal optical modes of asymmetric stretching of silica rings of different size. Additional characteristic silica vibrations appear at approximately 970 and $781 \mathrm{~cm}^{-1}$ (Figure 1), which are assigned to the $\mathrm{Si}-\mathrm{O}$ stretching of residual silanol groups in the silica network [25-27] and to symmetric Si-O-Si stretching [26], respectively. The peak at $897 \mathrm{~cm}^{-1}$ is most likely related to a $\mathrm{Si}-\mathrm{O}-\mathrm{Al}$ vibration. It should be noted that peaks detected at 970 and $897 \mathrm{~cm}^{-1}$ may contain contributions of the vinyl groups (i.e. $\mathrm{C}-\mathrm{H}$ wag of $\mathrm{CH}$ and $\mathrm{CH}_{2}$ moieties, respectively) [29]. Finally, the absorption bands at ca. 545 and $465 \mathrm{~cm}^{-1}$ have been attributed to the deformation of four-membered siloxane ring [26] and to a rocking mode of $\mathrm{Si}-\mathrm{O}-\mathrm{Si}$ moieties $[27,28,30]$, respectively.

The FTIR spectra of the film-coated alloy show a shift of the $\mathrm{Si}-\mathrm{O}-\mathrm{Si}$ asymmetric stretching bands to lower frequency with increasing VTMS concentration (i.e. this band is detected at1194, 1190, $1171,1168 \mathrm{~cm}^{-1}$ in $1 \mathrm{~V}, 2 \mathrm{~V}, 3 \mathrm{~V}$ and $4 \mathrm{~V}$ samples, respectively). This shift has been attributed to an enhancement of the porosity, which is provoked by the enlargement of both the $\mathrm{Si}-\mathrm{O}-\mathrm{Si}$ angles and the $\mathrm{Si}-\mathrm{O}$ bonds lengths $[25,27,28]$. According to Fidalgo et al. [25], the accommodation of larger hydrophobic groups produces structural changes in the silica network that involve the partial conversion of four- to six-fold rings. Thereby, structures become more porous and the average pore diameter increases. The same behavior has been attributed to the band at approximately $460 \mathrm{~cm}^{-1}$.

\subsubsection{Surface analysis}

The morphological aspects and compositions of the films were analyzed by SEM and EDX (Figure 2). SEM images show little change in the morphology and roughness of the AA2024 panels coated with different VTMS/TEOS ratios. The slots produced by the mechanical polishing performed prior to the immersion of the panels in the starting 
solutions are visible in all of the images. However, such slots were smoothed, in the cases of the $3 \mathrm{~V}$ and $4 \mathrm{~V}$ samples, which suggest that the preparation of films from solutions with greater VTMS/TEOS ratios promotes better substrate coverage. This supposition is supported by the increased $\mathrm{Si}$ concentration in the total EDX survey spectra of the $2 \mathrm{~V}$ and $3 \mathrm{~V}$ samples, which are presented in Figures $2 \mathrm{e}$ and $2 \mathrm{f}$.

Li et al. [12] studied triacetoxyvinylsilane sol-gel coatings on aluminum and copper. They found higher values of intermediate oxide layer resistance, associated to the interaction of $\mathrm{Me}-\mathrm{OH}$ on metallic surface and $\mathrm{Si}-\mathrm{OH}$ of the sol-gel films, resulting in the formation of Me-O-Si bonds, for $\mathrm{Al}$ coated samples than for $\mathrm{Cu}$ coated samples. According to these authors the $\mathrm{Al}$ metal is better passivated than $\mathrm{Cu}$ under ambient condition and the passive layer would help to develop a rather high barrier of intermediate layer for corrosion protection in the sol-gel-coated sample. In the specific case of the AA2024 alloy, which has a heterogeneous microstructure composed by intermetallics such as $\mathrm{Al}-\mathrm{Cu}, \mathrm{Al}-\mathrm{Cu}-\mathrm{Fe}-\mathrm{Mn}$ and $\mathrm{Al}-\mathrm{Cu}-\mathrm{Mg}[31,32]$, these copper-rich particles are expected to inhibit the uniform deposition of VTMS/TEOS films onto the alloy.

\subsubsection{Electrochemical measurements}

The corrosion performance of the AA2024 alloy samples coated with different ratios of TEOS and VTMS was evaluated by EIS while the samples were immersed in a $\mathrm{Cl}^{-}$ion-containing solution. Figure 3 depicts the Bode plots of the alloy samples coated with $1 \mathrm{~V}, 2 \mathrm{~V}, 3 \mathrm{~V}$ and $4 \mathrm{~V}$ films after $48 \mathrm{~h}, 72 \mathrm{~h}, 168 \mathrm{~h}$ and $360 \mathrm{~h}$ of immersion in 0.05 mol L $\mathrm{L}^{-1} \mathrm{NaCl}$ solution.

After $48 \mathrm{~h}$ at least three time constants were detected in Figure 3 for the alloy coated with $2 \mathrm{~V}, 3 \mathrm{~V}$ and $4 \mathrm{~V}$. The relaxation process at high frequency (approximately 
$10^{4} \mathrm{~Hz}$ ) is associated to the silane film while that at medium frequency (approximately $10^{3}$ a $10^{-1.5} \mathrm{~Hz}$ ) is related to an interfacial layer formed by $\mathrm{Si}-\mathrm{O}-\mathrm{Al}$ bonds and aluminum oxide [23,33]. The third time constant at low frequency (from $32.2 \mathrm{mHz}$ ) is due to corrosion activity. The Bode diagram of the $1 \mathrm{~V}$ specimens after $48 \mathrm{~h}$ shows a broad time constant at approximately $35 \mathrm{~Hz}$, due to an intermediate layer, whereas a second one, around $50 \mathrm{mHz}$, corresponds to the corrosion phenomenon. The surface of the $1 \mathrm{~V}$ film is more hydrophilic, thereby allowing electrolyte access [9] (i.e. it does not act as a physical barrier). The formation of the intermediate layer retards the degradation of the sample, since the overall impedance up to $72 \mathrm{~h}$ of the $1 \mathrm{~V}$ films is close to that of the $2 \mathrm{~V}$ films. The phase-angle values at high frequencies decrease with increasing exposure time for all films, even though such reduction is less pronounced for 3V samples.

The experimental data obtained for the VTMS/TEOS coatings after $72 \mathrm{~h}$ of immersion were fitted using the equivalent circuit $\mathrm{R}_{\mathrm{s}}\left(\mathrm{CPE}_{\mathrm{HF}}\left[\mathrm{R}_{\mathrm{HF}}\left(\mathrm{CPE} \mathrm{MF}_{\mathrm{MF}}\left[\mathrm{R}_{\mathrm{MF}} \mathrm{W}\right]\right)\right]\right)$, where $\mathrm{R}_{\mathrm{s}}$ represents the resistance between the AA2024 coated samples and the reference electrode, $\mathrm{R}_{\mathrm{HF}}$ and $\mathrm{CPE}_{\mathrm{HF}}$ are the resistance and capacitance, respectively, of the sol-gel film, $\mathrm{R}_{\mathrm{MF}}$ and $\mathrm{CPE}_{\mathrm{MF}}$ are the resistance and capacitance of the interfacial layer ( $\mathrm{Si}-\mathrm{O}-\mathrm{Al}$ and oxide film) and $\mathrm{W}$ is the Warburg impedance related to the diffusion process [2,23]. As previously mentioned, the relaxation process at high frequencies was not detected for $1 \mathrm{~V}$ samples; therefore, the fit was performed with only two time constants (i.e. $\mathrm{CPE}_{\mathrm{MF}}$ in parallel with $\mathrm{R}_{\mathrm{MF}}$ and $\mathrm{W}$ ). The CPE impedance is attributed to the distributed surface reactivity, the surface heterogeneity, the roughness and the porosity of electrode and to the current and potential distributions, which, in turn, are related to the electrode geometry [34]. The values obtained with the use of equivalent circuits are displayed in Table 2. Higher 
resistance and lower capacitance values at high and medium frequency ranges obtained in the simulation of $3 \mathrm{~V}$ samples demonstrate the beqst protection of this coating among the tested films.

In order to better understand the role of VTMS/TEOS ratio on the properties of formed silica network, temporal evolution of the resistance of the film $\left(\mathrm{R}_{\mathrm{HF}}\right)$ is depicted in Figure 4. After $360 \mathrm{~h}$, the time constant at high frequency disappears for $2 \mathrm{~V}$ and $4 \mathrm{~V}$ panels, whereas the $\mathrm{R}_{\mathrm{HF}}$ achieves $251.2 \Omega \mathrm{cm}^{2}$ for $3 \mathrm{~V}$ samples. These data confirm that the silica network of $3 \mathrm{~V}$ film enables a better barrier for uptake of aggressive ions during all the evaluated immersion time.

EIS analyses indicate an improvement in the corrosion performance when the VTMS concentration increases from $1 \%$ to $3 \%$. The vinyl groups presumably disrupt the integrity of the hydroxylated surface (i.e., the concentration of SiOH groups on the surface decreases) [35], enhancing the hydrophobicity and the barrier properties of the films. The Water Contact Angle measurements confirm this hypothesis since that the contact angle obtained was $61 \pm 2,70 \pm 1.5,75 \pm 1.5$ and $79 \pm 1.5$ for $1 \mathrm{~V}, 2 \mathrm{~V}, 3 \mathrm{~V}$ and 4V samples. Al-O-Si or $\mathrm{Me}-\mathrm{O}-\mathrm{Si}$ bonds are hydrolytically unstable. Thus, when a large amount of water penetrates into the silica network, the $\mathrm{Al}-\mathrm{O}-\mathrm{Si}$ bonds are hydrolyzed, which results in regeneration of the $\mathrm{AlOH}$ and $\mathrm{SiOH}$ hydrophilic groups [33]. Accordingly, the hydrophobicity of the outermost layer is essential to reduce the penetration of the electrolyte and to maintain the adhesion between the silane and the metal surface. These features explain the better performance of the $3 \mathrm{~V}$ films.

The results shown in the present study are fully consistent with those reported by Liu et al. [36], who found that coatings produced by mixing up to $20 \mathrm{wt} \%$ of TEOS with silanes, such as VTMS, 3-[(methacryloxy)propyl] trimethoxysilane and 3glycidoxypropyltrimethoxysilane, exhibit better anticorrosion properties than those 
produced without TEOS. However, the anticorrosive behavior was found to deteriorate when the concentration of TEOS exceeded $25-30 \mathrm{wt} \%$.

The EIS data obtained for $4 \mathrm{~V}$ are in agreement with the shift to lower wavenumber of the $\mathrm{Si}-\mathrm{O}$ asymmetric stretching $\left(c a .1190 \mathrm{~cm}^{-1}\right)$ observed in the FTIR spectra when the VTMS concentration was increased. This frequency shift was attributed to the formation of a more porous silica structure, which does not behave as an effective barrier. Consequently, AA2024 samples coated with 4V exhibit lower resistance at high frequencies $\left(359.6 \Omega \mathrm{cm}^{2}\right)$ than $2 \mathrm{~V}\left(745.6 \Omega \mathrm{cm}^{2}\right)$ after $72 \mathrm{~h}$. Moreover, the easier access of electrolyte through the pores reduces the Warburg impedance and the resistance of the intermediate layer in comparison to alloy coated with a lower concentration of VTMS (e.g. $2 \mathrm{~V}$ panels). In this case, the influence of the porosity is greater than that of the hydrophobicity provided by the vinyl groups.

\subsection{Evaluation of EDTPO incorporation into 3V matrix}

Taking into account the good results obtained with the starting solution composed by $46 \%$ water, $50 \%$ ethanol, $3 \%$ VTMS and $1 \%$ TEOS, which provide an equilibrium between hydrophobicity and porosity, the incorporation of an phosphonic acid was examined to further enhance the corrosion protection.

\subsubsection{Electrochemical and surface analysis}

Figure 5 depicts the EIS spectra of AA2024 substrates coated with 3V films that incorporate different amounts of EDTPO. The Bode spectra of the films containing EDTPO, after $24 \mathrm{~h}$ immersed in chloride solution, were characterized by the presence of two time constants. For the $3 \mathrm{VE} 4$ sample, the first one was centered at $4 \mathrm{kHz}$ and the second one was centered at $165 \mathrm{mHz}$; for the 3VE5 sample, the time constants were 
displaced to $10 \mathrm{kHz}$ and $103 \mathrm{mHz}$, respectively. High values for the impedance modulus (greater than $10^{6.3} \Omega$ ) were detected at low frequencies. After $24 \mathrm{~h}$, the maximum phase angle at high frequency was $-46.6,-75.3$ and $-76.2^{\circ}$ for the $3 \mathrm{~V}, 3 \mathrm{VE} 5$ and $3 \mathrm{VE} 4$ samples, respectively; these angles decreased to $-32.9,-70.7$ and $-61.5^{\circ}$ after $168 \mathrm{~h}$. A significant increase in the phase angle at high frequencies and in impedance modulus was achieved with the doped systems, which indicates an enhancement of the protective character.

Notably, the third time constant for the 3VE4 coating, which is associated with the corrosion process, began at the same immersion time as that for the film without EDTPO (3V). However, at all immersion times, this relaxation process started at a lower frequency for the $3 \mathrm{VE} 4$ samples in comparison to $3 \mathrm{~V}$ panels. For example, the Bode plots show after $72 \mathrm{~h} / 168 \mathrm{~h}$, that the third time constant begins at $20.1 / 40.6$ $\mathrm{mHz}$ and 32.2 / $64.8 \mathrm{mHz}$ for substrates coated with $3 \mathrm{VE} 4$ and $3 \mathrm{~V}$, respectively. Furthermore, the 3VE4 panels exhibited a greater impedance modulus value, which indicates the protection afforded by this film in comparison to $3 \mathrm{~V}$. However, for exposure times greater than $48 \mathrm{~h}$ the overall impedance values of $3 \mathrm{VE} 4$ samples were approximately one order of magnitude lower than those obtained for 3VE5. Moreover, the EIS plots of the substrate coated with 3VE5 exhibited only two time constants, even after prolonged immersion time. These features reveal the lower performance of 3VE4 with respect to $3 \mathrm{VE5}$.

The SEM image displayed in Figure 6a shows that the polished lines of the metallic substrate were not visible in the 3VE5 samples. Furthermore, the total EDX spectrum (Figure 6c) exhibited an intense peak of $\mathrm{Si}$ and a tiny peak of $\mathrm{Al}$, which indicates that the alloy surface is almost entirely covered. In contrast, the SEM image of 3VE4 (Figure 6b) shows agglomerations and uncoated zones, where the metallic 
roughness is observable. The EDX spectrum of these agglomerations (Figure 6d) shows $\mathrm{Si}, \mathrm{O}$ and $\mathrm{C}$, evidencing are accumulations of silica. In these agglomerations, the evaporation rate of ethanol and water as well as the film shrinkage are most likely different from those in other zones. Differences in evaporation rates and shrinkage produce defects that act as a preferential pathway to electrolyte access and therefore impair the phosphonic action. The high concentration of carbon can be attributed to the carbon coating applied to the sample before SEM/EDX analyses.

Experimental data obtained for all the immersion times of 3VE5 and the initial stages (1h and $24 \mathrm{~h}$ ) of both $3 \mathrm{VE} 4$ and $3 \mathrm{~V}$ were fitted using the equivalent circuit (EC) $\mathrm{R}_{\mathrm{s}}\left(\mathrm{CPE}_{\mathrm{HF}}\left[\mathrm{R}_{\mathrm{HF}}\left(\mathrm{CPE}_{\mathrm{MF}} \mathrm{R}_{\mathrm{MF}}\right)\right]\right)$, where the definitions of $\mathrm{R}_{\mathrm{S}}, \mathrm{R}_{\mathrm{HF}}, \mathrm{CPE}_{\mathrm{HF}}, \mathrm{R}_{\mathrm{MF}}$ and $\mathrm{CPE} \mathrm{EF}_{\mathrm{MF}}$ are identical to those described above. After $48 \mathrm{~h}$ a third relaxation process at lower frequencies is detected, which was fitted by including a Warburg element in this EC, and it is related to the development of corrosion activity. In order to assess the influence of the EDTPO concentration on the corrosion protection properties, Figures 7 and 8 depict the temporal evolution of parameters obtained from the ECs for the coated systems.

The $\mathrm{R}_{\mathrm{HF}}$ values are higher for the two EDTPO-containing systems than for the $3 \mathrm{~V}$ panels and the values of this parameter decreased when the immersion was increased. The later observation evidences the deterioration of the coating since a decrease in $\mathrm{R}_{\mathrm{HF}}$ value indicates an augmentation of the number of pores and channels whereby the electrolyte reaches the interfacial layer [2]. For $3 \mathrm{~V}$ the $\mathrm{R}_{\mathrm{HF}}$ after $1 \mathrm{~h}$ of immersion into the chloride-containing solution is small, $1834 \Omega \mathrm{cm}^{2}$ and decreased to $651.1 \Omega \mathrm{cm}^{2}$ after $168 \mathrm{~h}$. In contrast, after $24 \mathrm{~h}$ the $\mathrm{R}_{\mathrm{HF}}$ of the alloy coated with $3 \mathrm{VE} 5$ and $3 \mathrm{VE} 4$ is 10.95 and $9.75 \mathrm{k} \Omega \mathrm{cm}^{2}$, respectively, remaining in the order of $\mathrm{k} \Omega \mathrm{cm}^{2}$ until 168 and $360 \mathrm{~h}$ of immersion for $3 \operatorname{VE} 4\left(3.55 \mathrm{k} \Omega \mathrm{cm}^{2}\right)$ and $3 \operatorname{VE} 5\left(4.37 \mathrm{k} \Omega \mathrm{cm}^{2}\right)$, 
respectively. The $\mathrm{CPE}_{\mathrm{HF}}$ shows the opposite tendency, suggesting an increase of adsorbed water in the silica network [2,37]. After $48 \mathrm{~h}$ of immersion the $\mathrm{CPE}_{\mathrm{HF}}$ is 0.057 , 0.14 and $0.58 \mu \mathrm{Fcm}^{-2} \mathrm{~s}^{\mathrm{n}-1}$ for $3 \mathrm{VE} 5,3 \mathrm{VE} 4$ and $3 \mathrm{~V}$, respectively (Figure 7). These results appointed that the outermost layer formed from starting solution containing $3.75 \times 10^{-5}$ mol $\mathrm{L}^{-1}$ propitiate the development of the most efficient barrier properties for corrosion protection.

The quality of the intermediate layer formed between the silica network and the metallic substrate is essential for corrosion protection because it represents the last obstacle before the corrosive initiators access the metallic surface, an assessment of this layer being therefore justified. The $\mathrm{R}_{\mathrm{MF}}$ values found for $3 \mathrm{~V}, 3 \mathrm{VE} 5,3 \mathrm{VE} 4$ samples were $3.17,28.71,5.54 \mathrm{M} \Omega \mathrm{cm}^{2}$ after $24 \mathrm{~h}$, respectively, decreasing to $0.28,3.12,0.38 \mathrm{M} \Omega \mathrm{cm}^{2}$ after $48 \mathrm{~h}$ (Figure 8). After $360 \mathrm{~h}$ of immersion, the alloy coated with 3 VE5 exhibited values $\left(0.58 \mathrm{M} \Omega \mathrm{cm}^{2}\right)$ greater than those observed for 3V and 3VE4 after 48h. Besides, the $\mathrm{CPE}_{\mathrm{MF}}$ increases with the immersion time for all samples, even though this increment was lower for 3VE5 than for 3VE4 and 3V. The values exhibited after $360 \mathrm{~h}$ of immersion were $10.22,38.48$ and $36.25 \mu \mathrm{F} \mathrm{cm} \mathrm{cm}^{-2} \mathrm{~s}^{\mathrm{n}-1}$ for $3 \mathrm{VE} 5,3 \mathrm{VE} 4$ and $3 \mathrm{~V}$, respectively.

These results suggest that the phosphonic acid improves both the silica network and the intermediate layer. Firstly, an improvement in the silica network occurs with phosphonic acid incorporation. We proposed [23] that a new bond Si-O-P can be formed resulting in better properties as can be detected by parameters values at high frequency obtained with the adequate EDTPO concentration. Secondly, the intermediate layer formed by mixing silane and phosphonic acid is more compact, (i.e. a good interaction occurs between this system and metallic surface). The values of resistance and capacitance obtained for 3VE5 indicate that the intermediate layer is better formed 
with this EDTPO concentration, triggering in the retardation of the relaxation process at low frequency. Maege et al.[38] and Thissen et al.[39] described the coordination of phosphonic acid onto aluminum surface through the formation of $\mathrm{Al}-\mathrm{O}-\mathrm{P}$ bonds. Results obtained in the present study allow us to propose that the intermediate layer is composed by both $\mathrm{Si}-\mathrm{O}-\mathrm{Me}$ and $\mathrm{P}-\mathrm{O}-\mathrm{Me}$ bonds. The $\mathrm{P}-\mathrm{O}-\mathrm{Me}$ linkage is stronger and more stable than other acids [20]. Presumably, $\mathrm{P}-\mathrm{O}-\mathrm{Me}$ bonds are less susceptible to hydrolysis than the $\mathrm{Si}-\mathrm{O}-\mathrm{Me}$, explaining the excellent results found for $3 \mathrm{VE5}$.

\subsubsection{Spectroscopy characterization by FTIR-RA}

The surfaces of EDTPO-containing films were studied by FTIR spectroscopy. The resulting spectra are compared in Figure 9 with those obtained for the $3 \mathrm{~V}$ film.

An inspection of the FTIR spectra indicates that the spectrum of the 3VE5 sample exhibits the same bands that the spectrum of $3 \mathrm{~V}$ (Figure 9). A complementary study was performed by Raman spectroscopy.However, the phosphonate groups are also not detected and for sake the simplicity the Raman data are not present here. This similarity suggests that the phosphonic acid is localized at the interior zones of the films.

3.2.3 XPS analysis of AA2024 coated with VTMS/TEOS (3V) and VTMS/TEOS/phosphonic acid systems (3VE5)

To further investigate the structure of the coated AA2024, high resolution spectra of $\mathrm{A} 12 \mathrm{p}_{3 / 2}, \mathrm{Si} 2 \mathrm{p}_{3 / 2}, \mathrm{O} 1 \mathrm{~s}$ and $\mathrm{P} 2 \mathrm{p}$ were recorded after 0 and 40 min of sputtering. These spectra, together with their respective deconvoluted curves, are shown in Figure 10. 
The small A12p peak (Figure 10a) of the AA2024 coated with 3V and 3VE5 was initially located at $73.3 \mathrm{eV}$. Deconvoluted peaks for $0 \mathrm{~min}$ are not displayed due to the low signal-to-noise ratio. The Al2p peak after 40 min of sputtering (Figure 10b) was deconvoluted into three components. The curves centered at 72.9 and $74.2 \mathrm{eV}$ have been attributed to $\mathrm{Si}-\mathrm{O}-\mathrm{Al}$ linkages [40] and oxide aluminum [40,41], respectively, whereas the component at $71.2 \mathrm{eV}$ has been attributed to metallic contribution $[16,40,42]$. Hoque et al.[16] identified peaks centered at $71.4,71.9,72.3,73.6$ and $74.3 \mathrm{eV}$ in aluminum coated with $1 H, 1 H, 2 H, 2 H$-perfluorodecyldimethylchlorosilane and at 71.2, 71.7, 72.2, 73.9 and $74.6 \mathrm{eV}$ for aluminum coated with $1 H, 1 H, 2 H, 2 H$-perfluorodecylphosphonic films. The own authors attributed the two peaks at higher binding energies to the $\mathrm{Si}-\mathrm{O}-$ $\mathrm{Al}$ and $\mathrm{P}-\mathrm{O}-\mathrm{Al}$ linkages, respectively [16]. Thus, the detection of separated $\mathrm{Si}-\mathrm{O}-\mathrm{Al}$ and $\mathrm{P}-\mathrm{O}-\mathrm{Al}$ linkages in the hybrid system under study (i.e., silica and phosphonate) is expected to be difficult. Presumably, the component attributed to $\mathrm{Si}-\mathrm{O}-\mathrm{Al}$ for $3 \mathrm{VE} 5$ also contains contributions from the $\mathrm{P}-\mathrm{O}-\mathrm{Al}$ bonds.

To understand the chemical environment of the oxygen contained in the hybrid film, the O1s peak of the initial spectra was deconvoluted into two curves with peaks centered at $531.3 \mathrm{eV}$ and $532.7 \mathrm{eV}$ (Figure 10c). The peak at $531.3 \mathrm{eV}$ is related to aluminum oxide/hydroxide in the AA2024 metallic surface [40,41], whereas the peak at $532.7 \mathrm{eV}$ has been attributed to $\mathrm{Si}-\mathrm{O}-\mathrm{Si}$ bonds in the silica network [43]. A third peak at $533.6 \mathrm{eV}$, which was attributed to phosphorus compounds, was detected for the $3 \mathrm{VE} 5$ samples after $40 \mathrm{~min}$ (Figure 10d). Tsud et al. [44] reported the adsorption of phenyl phosphonic acid on amorphous alumina. Their XPS analysis revealed two components in the $\mathrm{O} 1 \mathrm{~s}$ peak: one at $532.2 \mathrm{eV}$ and another at $533.4 \mathrm{eV}$, which were attributed to $\mathrm{Al}_{2} \mathrm{O}_{3}$ and the $\mathrm{Al}-\mathrm{O}-\mathrm{P}$ functional group, respectively [44]. Previous works associated the component with a binding energy of $533.8 \mathrm{eV}$ to $\mathrm{P}=\mathrm{O}$ groups [20]. 
The deconvolution of the Si2p spectra initially recorded for the $3 \mathrm{~V}$ and 3 VE5 films (Figure 10e) resulted in a single component centered at $103.2 \mathrm{eV}$, which was assigned to the $\mathrm{Si}-\mathrm{O}-\mathrm{Si}$ linkages in the silica network [45]. With increasing of time profiling (Figure 10f), the maximum intensity of silicon peak is displaced to $102.9 \mathrm{eV}$. Beccaria et al. [46] associated the peak centered at $102.5 \mathrm{eV}$ to silicon bonded to aluminum oxide ( $\mathrm{Si}-\mathrm{O}-\mathrm{Al})$. Thus, the shift to lower energy observed in the present work can indicate changes in the silicon neighboring (i.e. beyond of silicon oxide contain contribution of $\mathrm{Si}-\mathrm{O}-\mathrm{Al})$.

Phosphorus was detected only after 40 min of sputtering time, presenting 3VE5 sample one peak of $\mathrm{P} 2 \mathrm{p}$ at $133.0 \mathrm{eV}$ (Figure $10 \mathrm{~g}$ ). This peak is very broad and was deconvoluted into two curves centered at $132.9 \mathrm{eV}$ and $134.6 \mathrm{eV}$, which correspond to $\mathrm{P}-\mathrm{O}-\mathrm{Metal}$ and $\mathrm{P}=\mathrm{O}$ bonds, respectively [47]. We assumed that the phosphorus forms stable Al-O-P linkages. A mechanism for the deposition of phosphonic acid/silica onto aluminum alloy was proposed in previous work [48].

The XPS spectra of the $3 \mathrm{~V}$ samples revealed the preferential formation of $\mathrm{Si}-\mathrm{O}-$ $\mathrm{Si}$ and $\mathrm{Si}-\mathrm{O}-\mathrm{Al}$ linkages at the outermost and interfacial regions, respectively, whereas the spectra of the 3VE5 samples showed $\mathrm{Si}-\mathrm{O}-\mathrm{Si}$ linkages in a polymeric network and both $\mathrm{P}-\mathrm{O}-\mathrm{Al}$ and $\mathrm{Si}-\mathrm{O}-\mathrm{Al}$ linkages at the interfacial region between the coating and the metallic substrate.

\section{Conclusions}

The present work provides new insights about the influence of the variation of the VTMS/TEOS ratio on the performance of coatings for corrosion protection. The IR data showed the shift to lower wavenumber of the $\mathrm{Si}-\mathrm{O}-\mathrm{Si}$ asymmetric stretching induced by the increase in the VTMS concentration in the VTMS/TEOS hybrid sol-gel matrix, 
which suggests an enhancement of the porosity in the silica network. An improved corrosion resistance was obtained with sample $3 \mathrm{~V}$ (3\% VTMS/1\% TEOS) as determined by EIS analysis. Nevertheless, according to the SEM/EDX results, the generated films are not uniform impairing their anticorrosive efficiency.

EIS and SEM/EDX results revealed effective corrosion protection of AA2024 by the addition of $3.75 \times 10^{-5} \mathrm{~mol} \mathrm{~L}^{-1}$ phosphonic acid (EDTPO) to a VTMS/TEOS matrix. The formation of the silica network and $\mathrm{Si}-\mathrm{O}-\mathrm{Al}$ linkages were indicated by XPS for the hybrid sol-gel systems with and without EDTPO. Moreover, XPS data suggested that form P-O-Al linkages, which combined with the action of the silica network, may be responsible for the good anticorrosive behavior of the 3VE5 films.

The observed improvement in the anticorrosive performance achieved with the addition of an appropriate concentration of EDTPO into a hybrid sol-gel matrix opens a new potential approach in which the properties of the silica films and phosphonic acid are combined. Furthermore, excellent results were achieved with a high water concentration, which makes this system environmentally friendlier.

\section{Supporting Information:}

The observed FTIR bands and their respective assignments for sol-gel films with different VTMS/TEOS ratios and for films containing phosphonic acid are provided in Table S1.

\section{Acknowledgements}

Authors are grateful to the CNPq and Capes Brazilian Agencies. C.A and E.A. have been supported by MICINN and FEDER funds (MAT2012-34498) and by the DIUE of the Generalitat de Catalunya (contract number 2009SGR925). Authors thank NSERC Inter-American Collaboration Grant (Canada). 


\section{References}

[1] F. Zanotto, V. Grassi, A. Frignani, F. Zucchi, Mater. Chem. Phys. 129 (2011) 1-8

[2] M.L. Zheludkevich, R. Serra, M.F. Montemor, K.A. Yasakau, I.M.M. Salvado, M.G.S. Ferreira, Electrochim. Acta 51 (2005) 208-217.

[3] H. Shi, F. Liu, E. Han,Mater. Chem. Phys. 124 (2010) 291-297

[4] P.H. Suegama, H.G. de Melo, A.V. Benedetti, I.V. Aoki, Electrochim. Acta 54 (2009) 2655-2662.

[5] M.J. Juan-Díaz, M. Martínez-Ibáňez, M. Hernández-Escolano, L. Cabedo, R. Izquierdo, J. Suay, M. Gurruchaga, I. Goňi, Prog. Org. Coat. 77 (2014) 1799-180.

[6] M.S. Donley, R.A. Mantz, A.N. Khramov, V.N. Balbyshev, L.S. Kasten, D.J. Gaspar, Prog. Org. Coat. 47 (2003) 401- 415.

[7] B.N. Zand, M. Mahdavian, Electrochim. Acta 52 (2007) 6438-6442.

[8] M. Mohseni, M. Mirabedini, M. Hashemi, G.E. Thompson, Prog. Org. Coat. 57 (2006) 307-313.

[9] J.-M. Hu, L. Liu, J.-Q. Zhang, C.-N Cao, Prog. Org. Coat. 58 (2007) 265-271.

[10] J.B. Bajat, I. Milošev, Ž. Jovanović, R.M. Jančić-Heinemann, M. Dimitrijević, V.B. Mišković-Stanković, Corros. Sci. 52 (2010) 1060-1069.

[11] Y.-S. Li, P.B. Wright, R. Puritt, T. Tran, Spectrochim. Acta: Part A 60 (2004) 2759-2766.

[12] Y.-S. Li, A. Ba, M.S. Mahmood, Electrochim. Acta 53 (2008) 7859-7862.

[13] J. Flis, M. Kanoza,Electrochim. Acta 51 (2006) 2338-2345.

[14] G. Kong, J. Lu, S. Zhang, C. Che, H. Wu, Surf. Coat. Technol. 205 (2010) 545550 .

[15] J. Hu, Q. Li, X. Zhang, W. Kang, Prog. Org. Coat. 63 (2008) 13-17.

[16] E. Hoque, J.A. DeRose, P. Hoffmann, B. Bhushan,H. J. Mathieu, J. Phys. Chem. C 111 ( 2007)3956-3962.

[17] A. Paszternák, S. Stichleutner, I. Felhősi, Z. Keresztes , F. Nagy, E. Kuzmann, A. Vértes, Z. Homonnay, G. Pető, E. Kálmán,Electrochim. Acta 53 (2007) 337-345.

[18] G. Lecollinet, N. Delorme, M. Edely, A. Gibaud, J.-F.Bardeau, F. Hindré, F. Boury, D. Portet, Langmuir 25 (2009) 7828-7835.

[19] A. Pilbáth, I. Bertóti, I. Sajó, L. Nyikos , E. Kálmán, Appl. Surf. Sci. 255 (2008) 1841-1849.

[20] A. Raman, R. Quiñones, L. Barriger, R. Eastman, A.Parsi, E.S. Gawalt, Langmuir 26 (2006) 1747-1754. 
[21] E. Laiti, L.-O.Öhman, J. Nordin, S. Sjörberg, J. Colloid Interf. Sci.175 (1995) 230238.

[22] V. Dalmoro, J. H. Z. dos Santos, D. S. Azambuja, J. Solid State Electrochem. 16 (2012) 403-414.

[23] V. Dalmoro, J. H. Z. dos Santos, E. Armelin, C. Alemán, D. S. Azambuja, Corros. Sci. 60 (2012) 173-180.

[24] H. Yim, M. S. Kent, D. R. Tallant, M. J. Garcia, J. Majewski, Langmuir 21 (2005)4382-4392.

[25] A. Fidalgo, L. M. Ilharco, J. Non-Cryst. Solids 347 (2004) 128-137.

[26] D. L. Ou, A. B. Seddon, J. Non-Cryst. Solids 210 (1997) 187-203.

[27] P. Innocenzi, P. Falcaro, D. Grosso, F. Babonneau, J. Phys. Chem. B107 (2003) 4711-4717.

[28] P. Innocenzi, J. Non-Cryst. Solids 316 (2003) 309-319.

[29] N.B. Colthup, L.H. Daly, S.E. Wiberley, Introduction to Infrared and Raman Spectroscopy, third ed., Academic Press, San Diego, 1990.

[30] A. Fidalgo, L. M. Ilharco, J. Non-Cryst. Solids 283 (2001) 144-154.

[31] R.G. Buchheit, R.P. Grant, P.F. Hlava, B. Mckenzie, G.L. Zender, J. Electrochem. Soc.144 (1997) 2621-2628.

[32] A. Boag, A.E. Hughes, A.M. Glenn, T.H. Muster, D. McCulloch, Corros. Sci. 53 (2011) 17-26.

[33] D. Zhu, W.J. vanOoij, Electrochim. Acta 49 (2004) 1113-1125.

[34] J.-B. Jorcin, M. E. Orazem, N. Pébère, B. Tribollet, Electrochim. Acta 51 (2006) $1473-1479$.

[35] T. L. Metroke, J. S. Gandhi, A. Apblett,Prog. Org. Coat. 50 (2004) 231-246.

[36] Y. Liu, D. Sun, H. You, J. S. Chung, Appl. Surf. Sci. 246 (2005) 82-89.

[37] D. Raps, T. Hack, J. Wehr, M.L. Zheludkevich, A.C. Bastos, M.G.S. Ferreira, O. Nuyken, Corros. Sci. 51 (2009) 1012-1021.

[38] I. Maege, E. Jaehne, A. Henke, H-J. P. Adler, C. Bram, C. Jung, M. Stratmann, Prog. Org. Coat. 34 (1998) 1-12.

[39] P. Thissen, M, Valtiner, G. Grundmeier, Langmuir 26 (2010) 156-164.

[40] J.B. Bajat, I. Milošev, Ž. Jovanović, V.B. Mišković-Stanković, Appl. Surf. Sci. 256 (2010) 3508-3517. 
[41] C. D. Wanger, W. M. Riggs, L. E. Davis, J. F. Moulder, G. E. Muilenberg, Handbook of X-ray Photoelectron Spectroscopy Perkin-Elmer Corp., Ch. 2, Physical Electronics Division, Eden Prairie: Minnesota, USA, 1979.

[42] M. Giza, P. Thissen, G. Grundmeier, Langmuir 24 (2008) 8688-8694.

[43] F. Brusciotti, A. Batan, I. De Graeve, M. Wenkin, M. Biessemans, R. Willem, F. Reniers, J.J. Pireaux , M. Piens, J.Vereecken, H. Terryn, Surf. Coat. Technol. 205 (2010) 603-613.

[44] N. Tsud, M. Yoshitake, Surf. Sci. 601 (2007) 3060-3066.

[45] M.C. Capel-Sanchez, L. Barrio, J.M. Campos-Martin, J.L.G. Fierro, J. Colloid Interf. Sci. 277 (2004) 146-153.

[46] A.M. Beccaria, L Chiaruttini, Corros. Sci. 41 (1999) 885-899.

[47] T. Ishizaki, K. Teshima, Y. Masuda, M. Sakamoto, J. Colloid Interf. Sci. 360 (2011) 280-288.

[48] V. Dalmoro, J. H. Z. dos Santos, E. Armelin, C. Alemán, D. S. Azambuja, Appl. Surf. Sci.273 (2013) 758-768.

Table 1

Composition (v/v) of the different starting solutions, The labels used to identify these systems are also displayed.

\begin{tabular}{llllll}
\hline Ethanol & Water & VTMS & TEOS & EDTPO concentration $\left(\mathrm{mol} \mathrm{L}^{-1}\right)$ & Label \\
\hline 50 & 46 & 4 & - & & $4 \mathrm{~V}$ \\
50 & 46 & 3 & 1 & & $3 \mathrm{~V}$ \\
50 & 46 & 2 & 2 & & $2 \mathrm{~V}$ \\
50 & 46 & 1 & 3 & & $1 \mathrm{~V}$ \\
50 & 46 & 3 & 1 & $3.75 \times 10^{-5}$ & $3 \mathrm{VE5}$ \\
50 & 46 & 3 & 1 & $3.75 \times 10^{-4}$ & $3 \mathrm{VE4}$ \\
\hline
\end{tabular}

Table 2

Parameters of the silica films with different ratio TEOS/VTMS after $72 \mathrm{~h}$ of immersion in $0.05 \mathrm{~mol} \mathrm{~L}^{-1} \mathrm{NaCl}$ obtained from the fitting of the exper imental impedancespect ra with the equivalent circuit.

\begin{tabular}{|c|c|c|c|c|}
\hline & $1 \mathrm{~V}$ & $2 \mathrm{~V}$ & $3 \mathrm{~V}$ & $4 \mathrm{~V}$ \\
\hline Ecorr (mV/SCE) & -0.627 & -0.604 & $-0,607$ & $-0,632$ \\
\hline$R_{\mathrm{s}}\left(\Omega \mathrm{cm}^{2}\right)$ & 87.0 & 105.1 & 90.2 & 77.2 \\
\hline$R_{\mathrm{HF}}\left(\Omega \mathrm{cm}^{2}\right)$ & & 745.5 & 786.9 & 359.6 \\
\hline CPEHF $\left(\mu \mathrm{Fcm}^{-2} \mathrm{~s}^{n-1}\right)$ & & 2,03 & 0,94 & 7.46 \\
\hline$n_{\mathrm{HF}}$ & & 0.70 & 0.73 & 0.56 \\
\hline$R_{\mathrm{MF}}\left(\mathrm{k} \Omega \mathrm{cm}^{2}\right)$ & 44,2 & 46.75 & 847 & 25,70 \\
\hline $\mathrm{CPE}_{\mathrm{MF}}\left(\mu \mathrm{Fcm}^{-2} \mathrm{~s}^{n-1}\right)$ & 15,11 & 4,80 & 4,85 & 21,70 \\
\hline$n_{\mathrm{MF}}$ & 0.75 & 0.78 & 0.73 & 0,76 \\
\hline$W\left(\mathrm{k} \Omega \mathrm{cm}^{2} \mathrm{~s}^{1 / 2}\right)$ & 2.61 & 2,30 & 21,17 & 2.24 \\
\hline
\end{tabular}




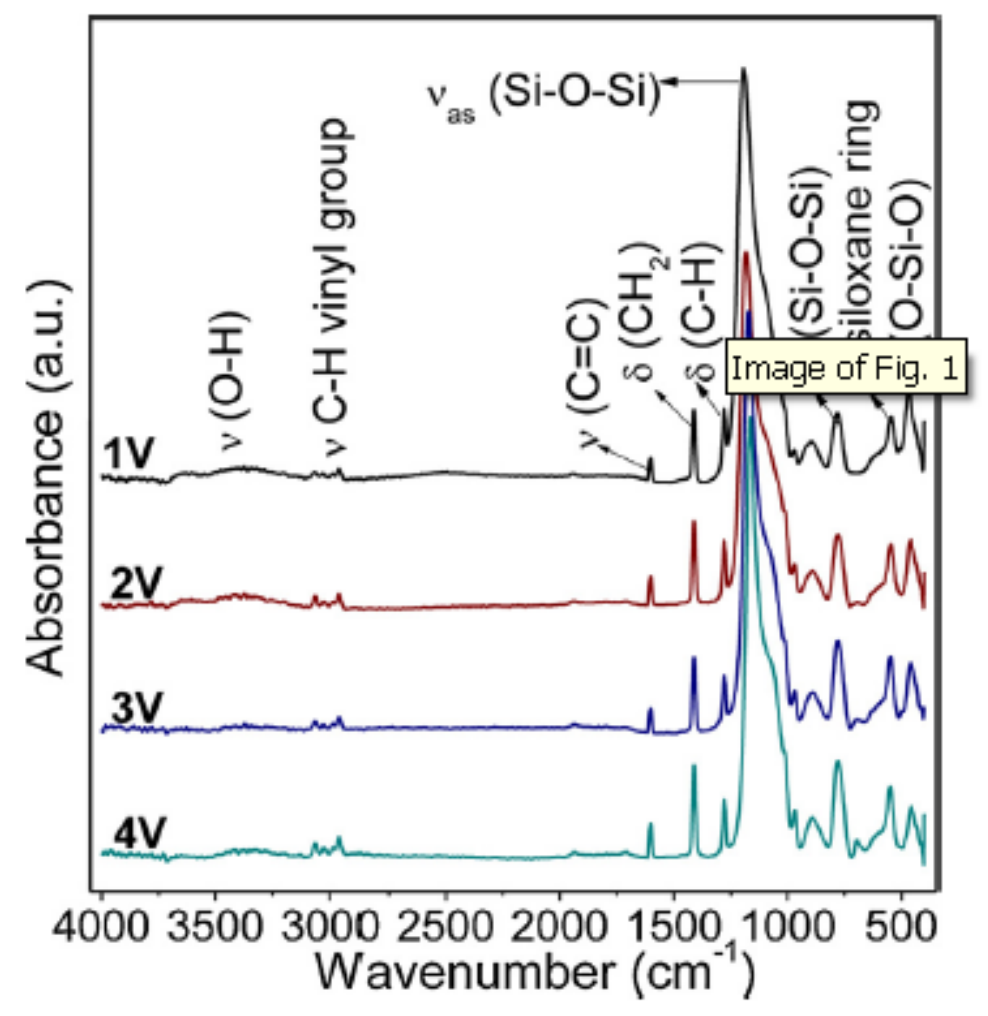

Figure 1. FTIR spectra of the sol-gel films with different VTMS/TEOS ratio deposited on AA2024 

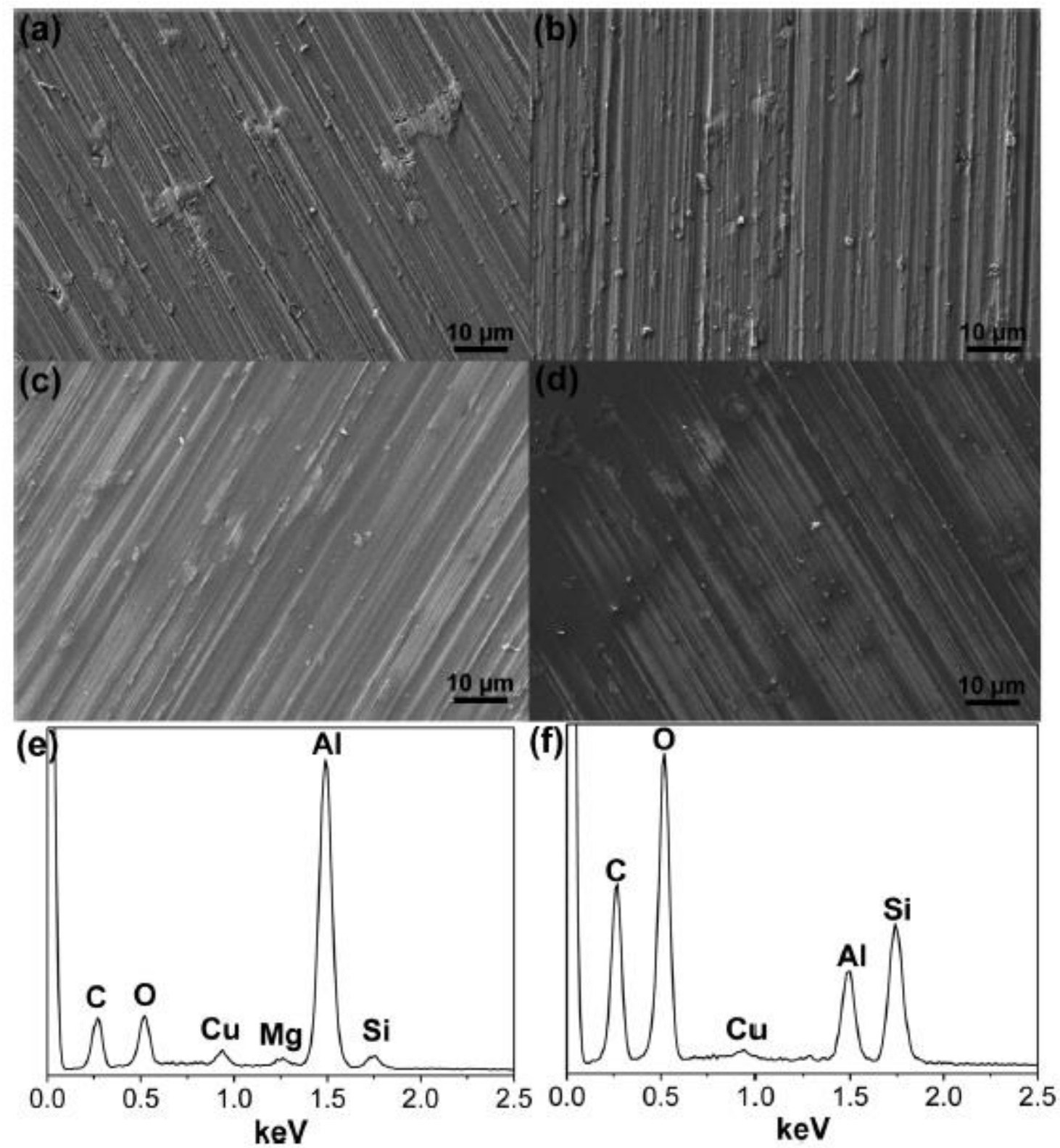

Figure 2. SEM micrographs of the AA2024 alloy coated with (a) $1 \mathrm{~V}$, (b) $2 \mathrm{~V}$, (c) $3 \mathrm{~V}$ and (d) $4 \mathrm{~V}$ films and total EDX analysis results for the (e) $2 \mathrm{~V}$ and (f) $3 \mathrm{~V}$ films. 

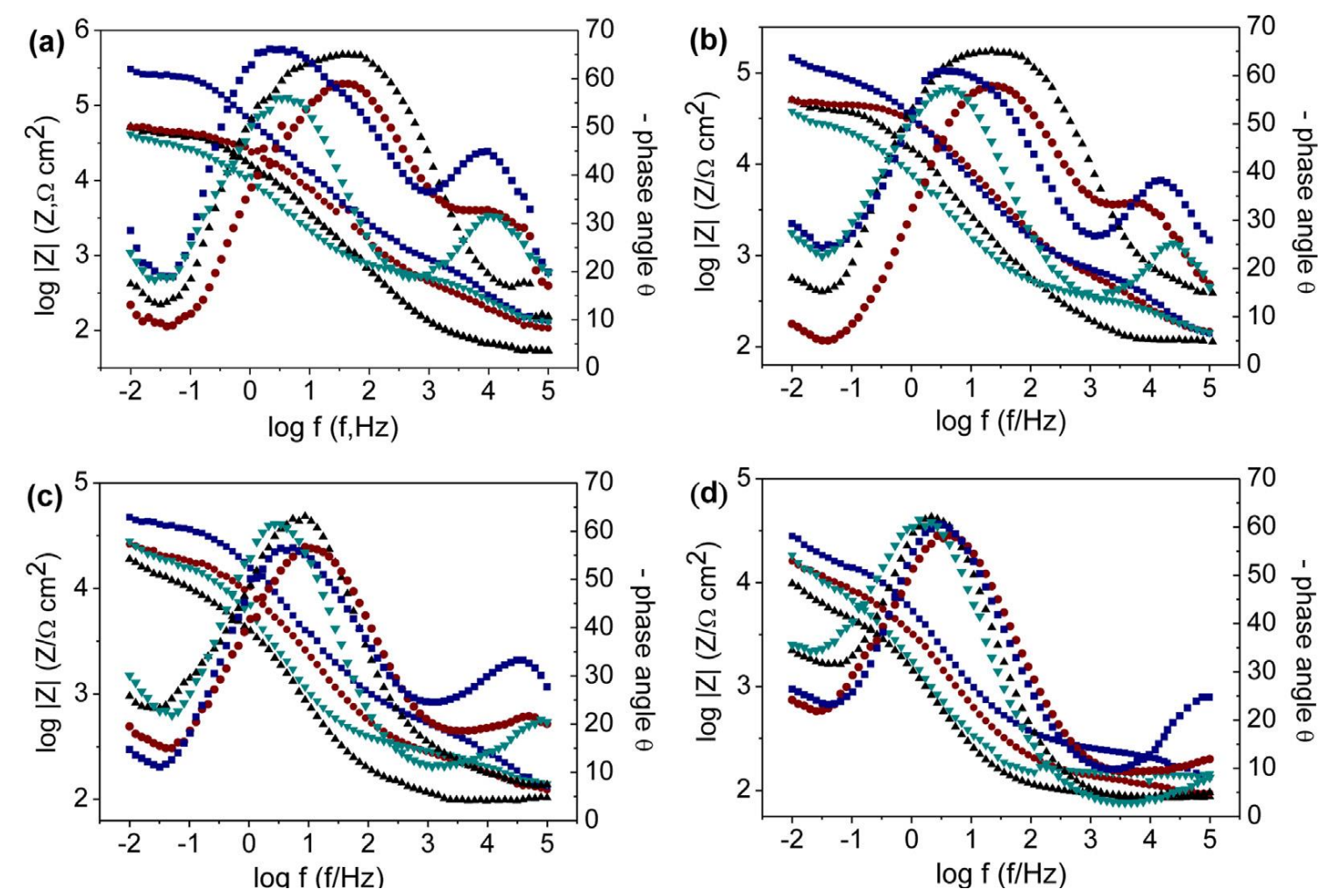

Figure 3. EIS spectra of the AA2024 alloy coated with $1 \mathrm{~V}(\boldsymbol{\Delta}), 2 \mathrm{~V}(\bullet), 3 \mathrm{~V}(\boldsymbol{\bullet})$ and $4 \mathrm{~V}$ $(\nabla)$ and $4 \mathrm{~V}$ after $24 \mathrm{~h}(\mathrm{a}), 72 \mathrm{~h} \mathrm{(b),} 168 \mathrm{~h}(\mathrm{c})$ and $360 \mathrm{~h}(\mathrm{~d})$ of immersion in 0.05 $\mathrm{mol} \cdot \mathrm{L}^{-1} \mathrm{NaCl}$. 


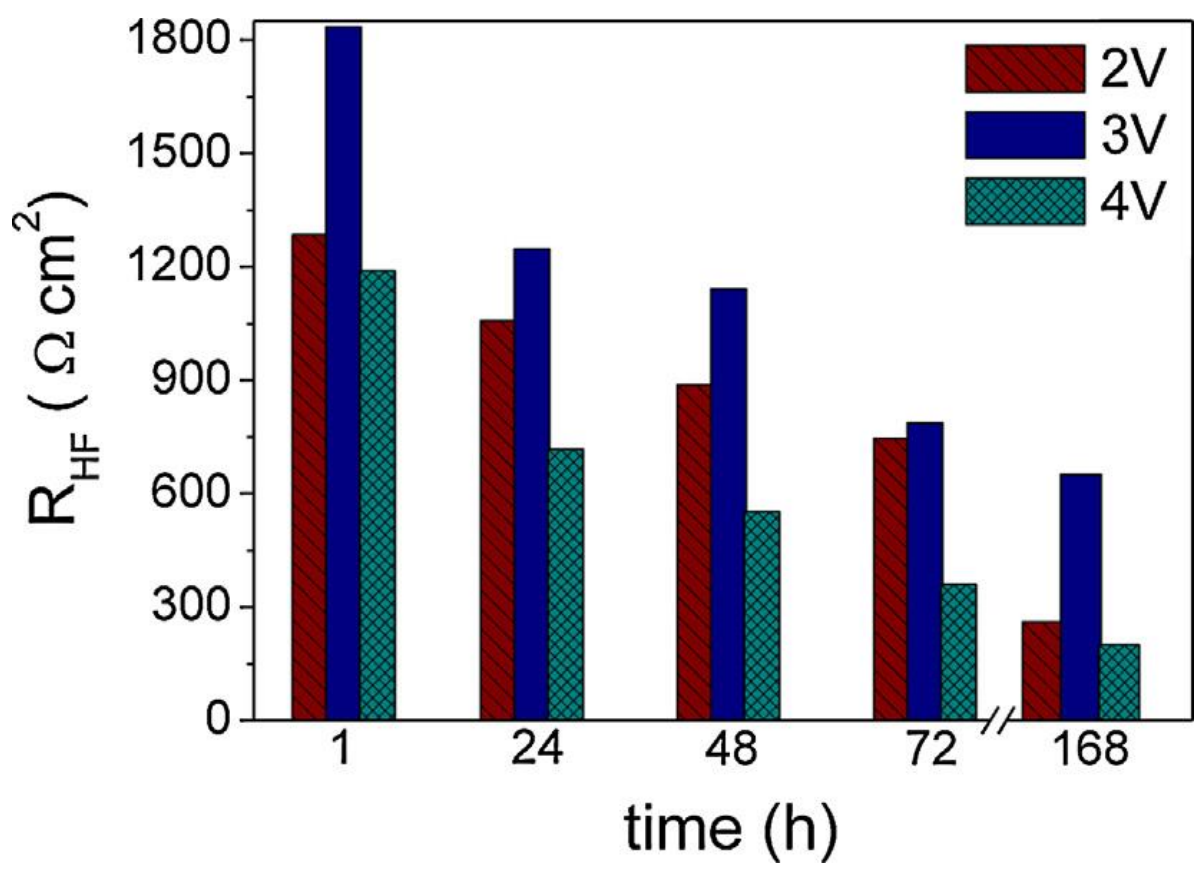

Figure 4. Resistance values of silica network for AA2024 coated with 2V, 3V and 4V films during the immersion time 

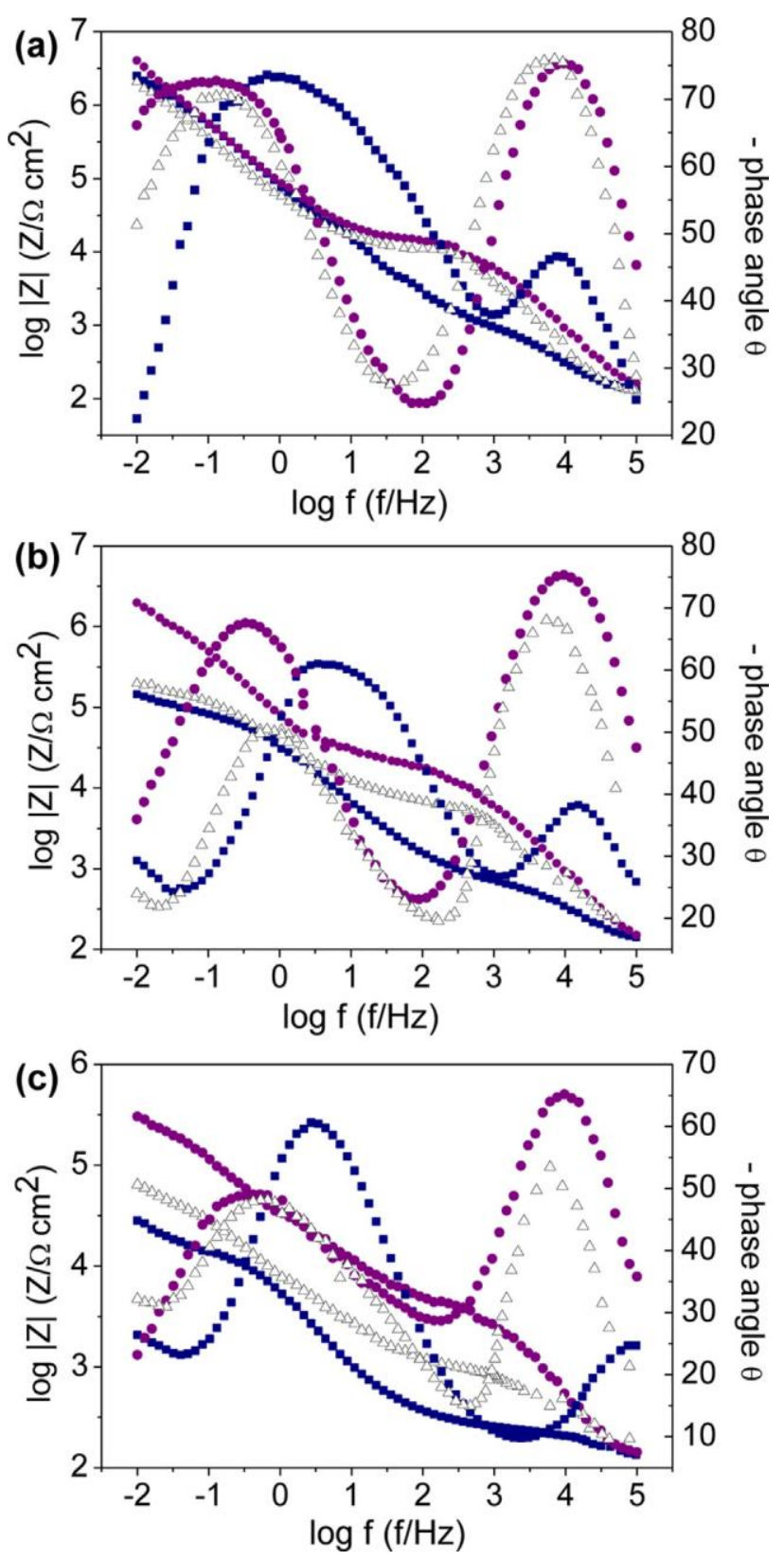

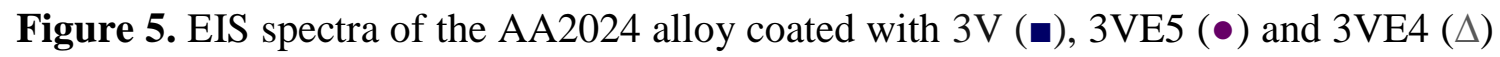
films after 24h (a), 72h (b), and 360h (c) of immersion in $0.05 \mathrm{~mol} \mathrm{~L}^{-1} \mathrm{NaCl}$. 

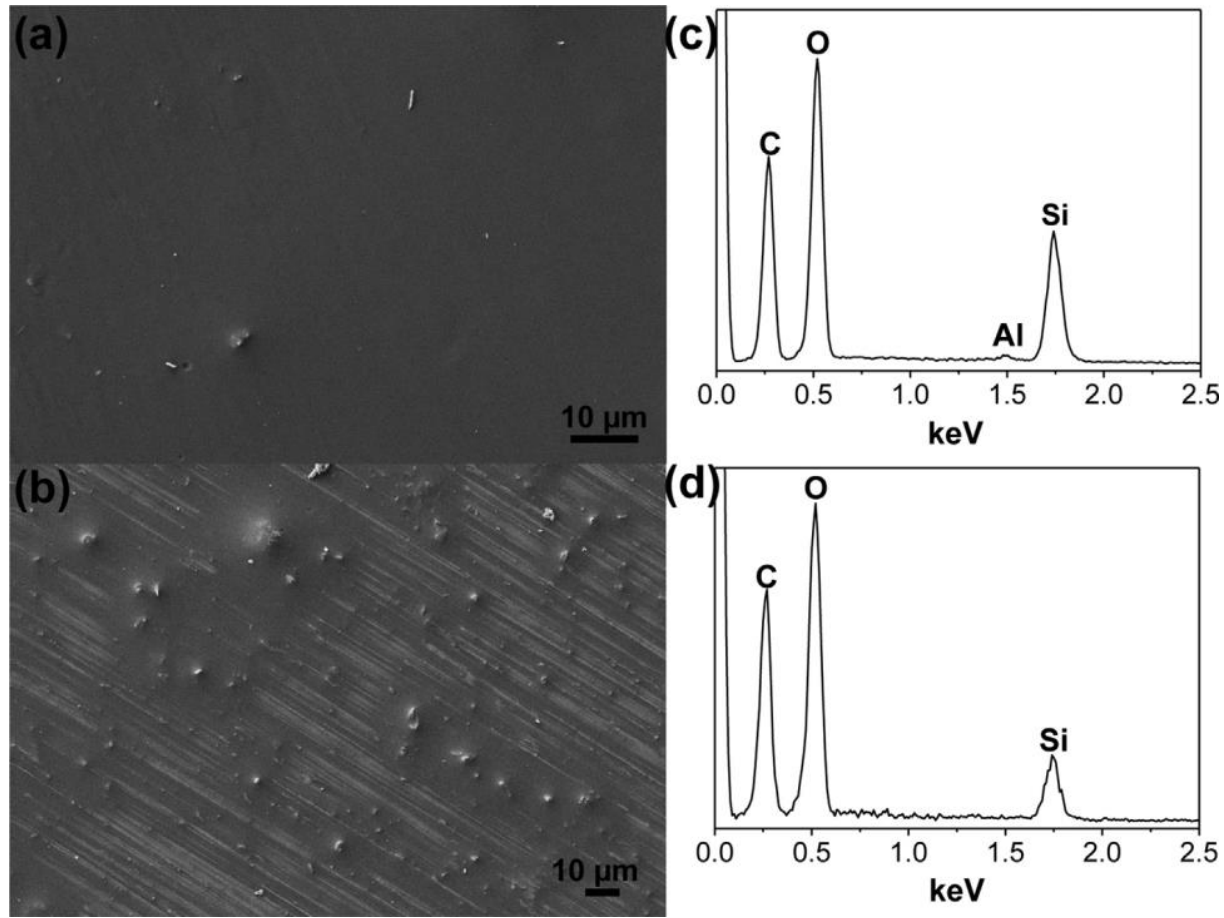

Figure 6. SEM micrographs of AA2024 coated with (a) 3VE5 and (b) 3VE4 and EDX spectra of (c) 3VE5 films and (d) white spots in 3VE4 films.

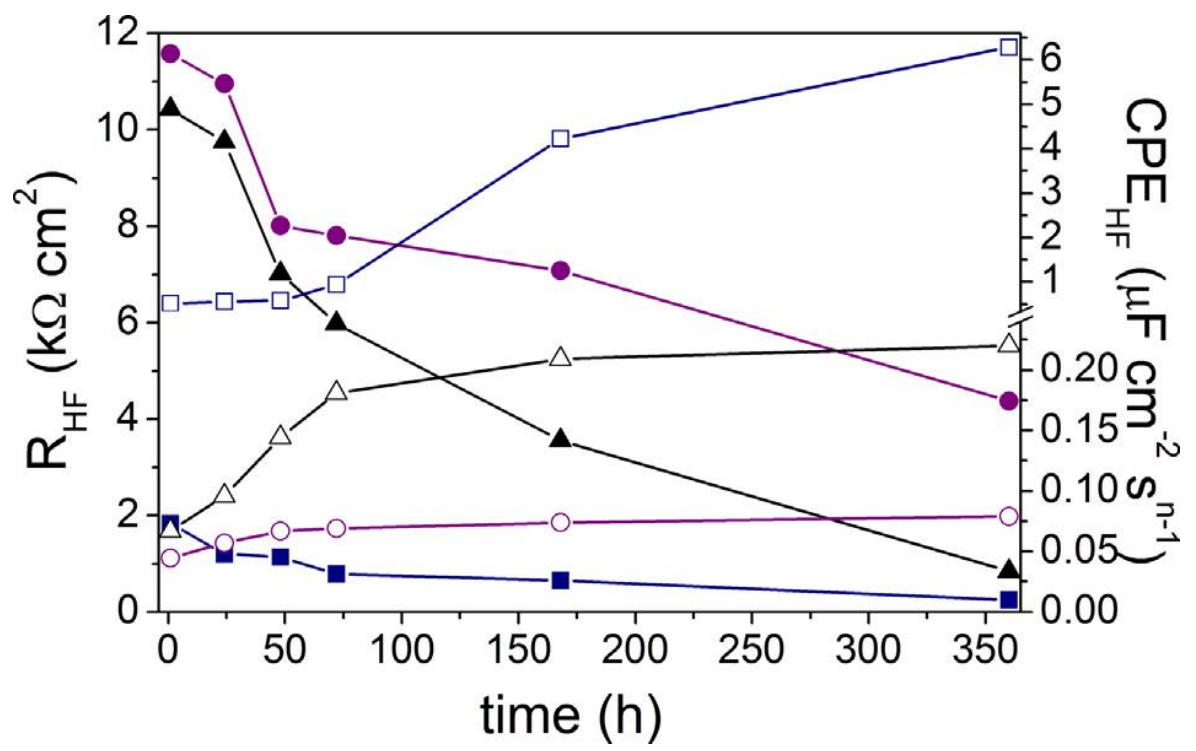

Figure 7. Evolution of the resistances (full symbols) and capacitances (open symbols) at high frequency of the 3V ( $\bullet), 3 \operatorname{VE} 5(\bullet)$ and 3VE4 ( $\Delta$ ) films for different immersion times. 


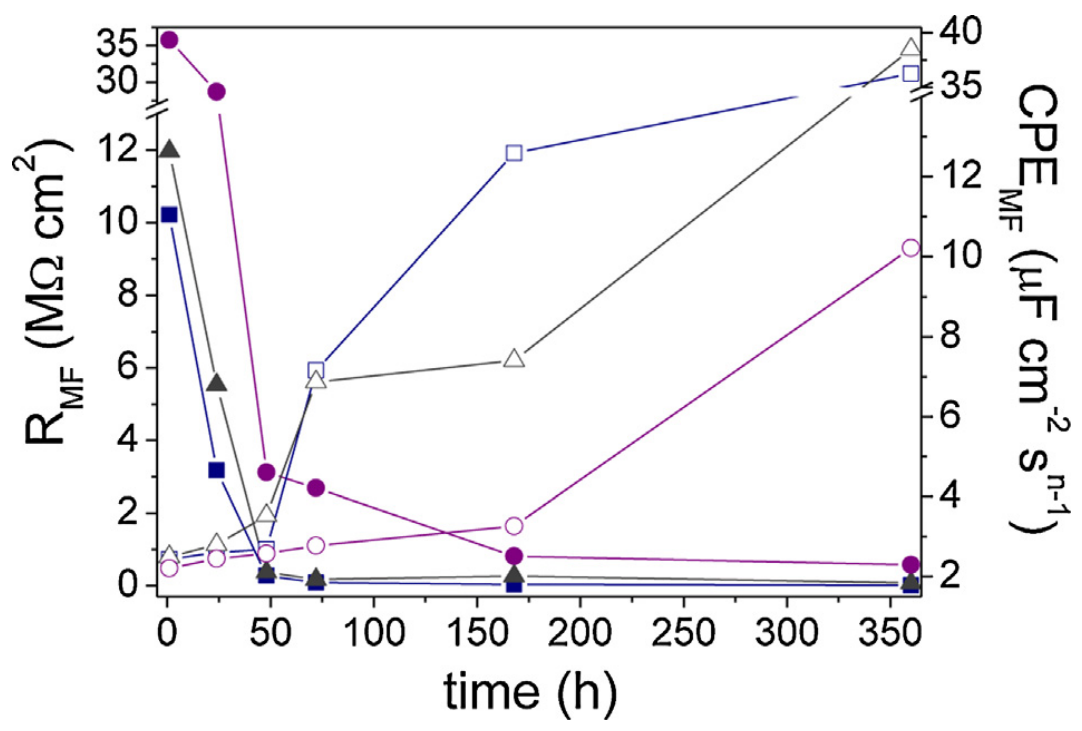

Figure 8. Evolution of the resistances (full symbols) and capacitances (open symbols) at medium frequency of the $3 \mathrm{~V}(\boldsymbol{\bullet}), 3 \mathrm{VE} 5(\bullet)$ and $3 \mathrm{VE} 4(\boldsymbol{\Delta})$ films for different immersion times.

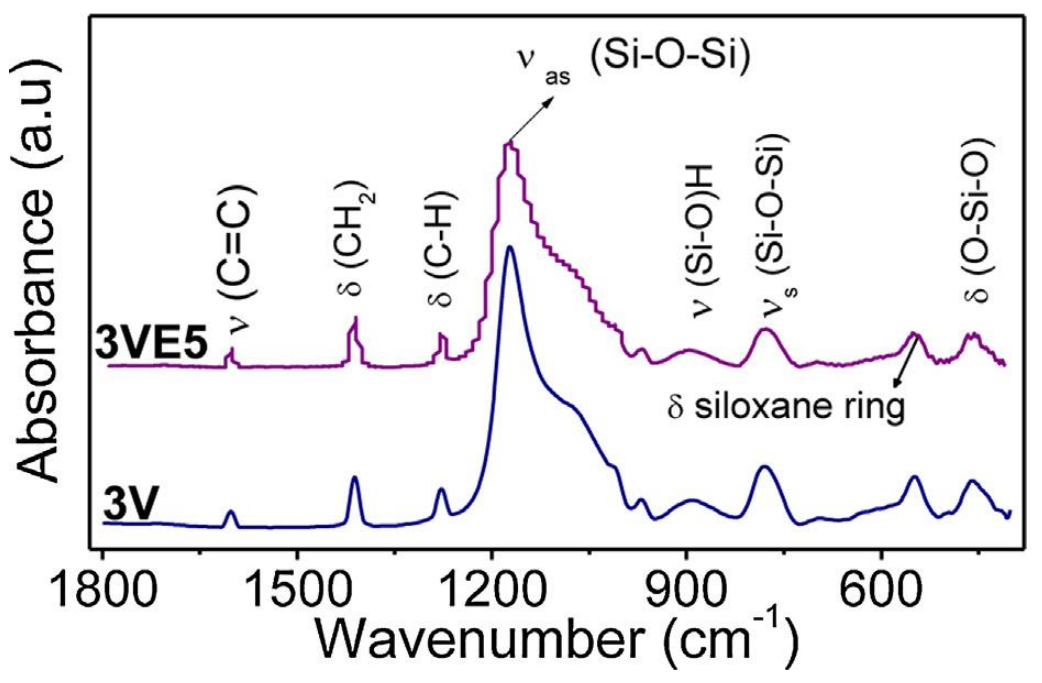

Figure 9. FTIR (a) and Raman spectra (b) of the 3V and 3VE5 films on AA2024 substrate. 

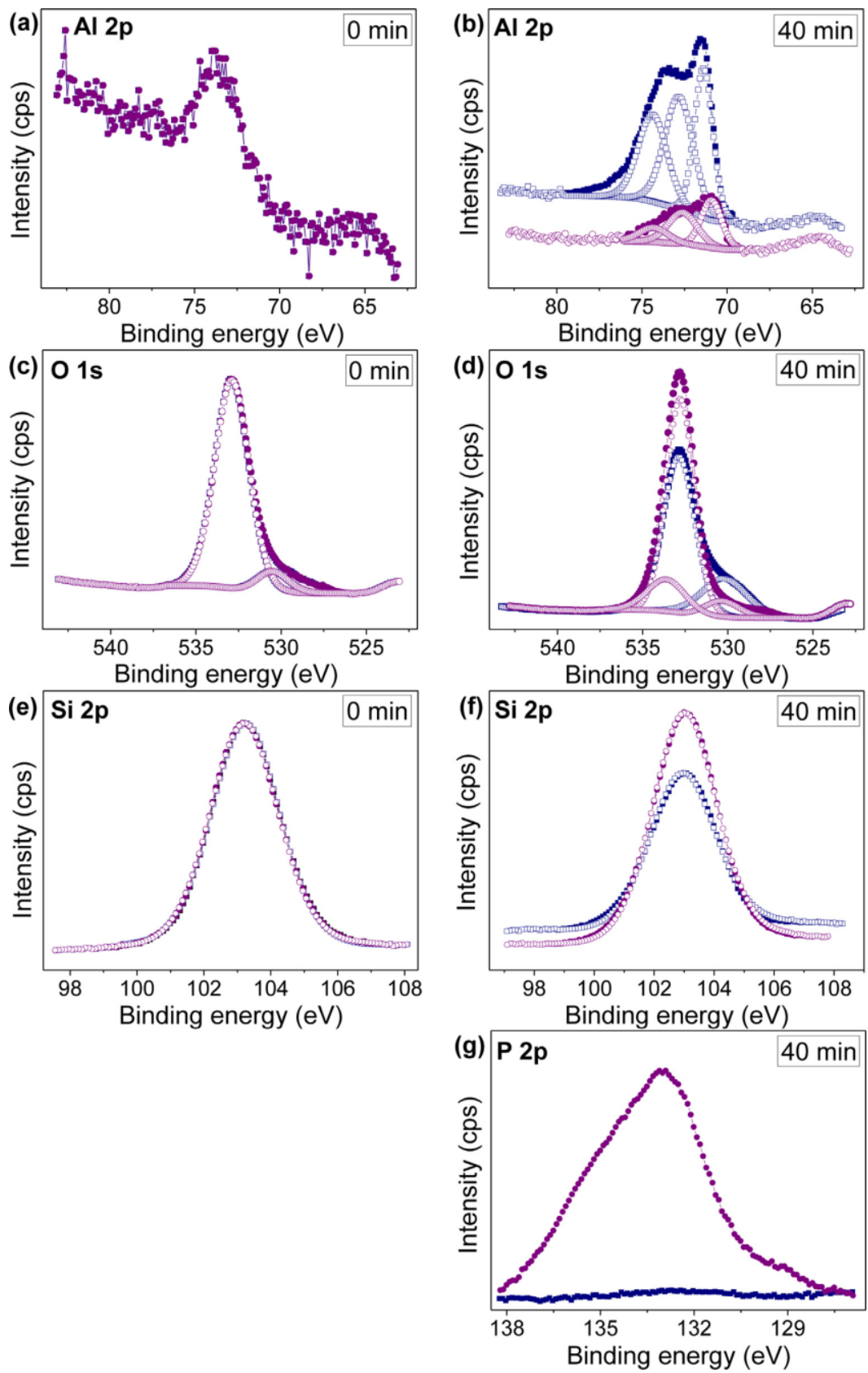

Figure 10. Normalized XPS high-resolution spectra (full symbols) recorded at depth profiling after 0 min for $\mathrm{Al} 2 \mathrm{p}$ (a), O 1s (c), Si 2p (e), and $40 \mathrm{~min}$ for $\mathrm{Al} 2 \mathrm{p} \mathrm{(b),} \mathrm{O} \mathrm{1s}$ (d), Si 2p (f), P 2p (g) of sputtering for AA2024 coated with 3V (ロ) and 3VE5 (•) films and their respective deconvoluted curves (open symbols). 